\title{
PAGES' Focus 4 Theme on Soils and Sediments: an Asian perspective
}

\author{
Thomas Hoffmann', R. Wasson ${ }^{2}$ and A. Ziegler
}

\begin{abstract}
Studying soil erosion and sediment transport is essential to understand human-induced environmental change. In Asia, this research is underrepresented despite pronounced and long-term anthropogenic impact - a new Asian working group on soils and sediments is filling this research gap.
\end{abstract}

PAGES' Focus 4 Theme on Soils and Sediments aims at providing understanding of the interactions between climate, human activity, soil erosion and sediment transport in fluvial systems through time. Although focused on the past, this research informs our understanding of the present and the future by documenting trajectories of change, investigating human interactions with fluvial systems, and delivers knowledge to enable societies to meet their goals on sustainable land use and river management.

The Soils and Sediments Theme derived from the former project "Land Use and Climate Impacts on Fluvial Systems during the period of agriculture" (LUCIFS), which was launched in 1994 (Wasson 1996). Recently, Hoffmann et al. (2010) re-defined its aims as: (1) quantifying land-use and climate change impacts on river-borne fluxes of water, sediment, $C$, $\mathrm{N}$, and $\mathrm{P}$; (2) identifying their key controls at the catchment scale; and (3) understanding the feedbacks on human society and biogeochemical cycles of long-term changes in the fluxes of these materials. In the same review article, the following research agenda was set out: (1) synthesizing the data available from existing case studies; (2) targeting research in data-poor regions; (3) integrating sediment, $C$, $\mathrm{N}$ and $\mathrm{P}$ fluxes; (4) quantifying the relative roles of allogenic and autogenic forcing on fluvial regimes, extreme events and sediment fluxes; (5) improving long-term river basin modeling; and (6) integrating the Theme with other working groups within PAGES.

Research under the banner of the Theme has progressed well in Europe (e.g. Hoffmann et al. 2007; Erkens et al. 2011; Verstreaten et al. 2009), North America (e.g. Trimble 1999; Stinchcomb et al. 2011) and Australia (Fryirs et al. 2007; Fryirs 2013). However, research on the long-term interaction of climate and land use and its impact on soils, sediments and river systems in Asia has lagged, except in China (see the contribution by Ran and Lu, this issue). Much of Asia is therefore a data-poor region in terms of fluvial research. This is critically important since Asia's physiography and climate supports a disproportionate number of the world's largest rivers by discharge, and is therefore the source of much of the sediment reaching the global oceans (Syvitski et al. 2005), and a major source of nutrients to the seas (e.g. Green et al. 2004). Moreover, Asia is home to a large fraction of Earth's people, and is the most rapidly urbanizing region on Earth with growing conurbations on the region's mega-deltas.

As in Europe, land use by clearing, settled cultivation, and urbanization has a long history in Asia. Also, and unlike in Europe and the Americas, deforestation and settled agriculture are now spreading rapidly in Asian areas previously only slightly impacted by humans. Therefore some catchments have been subjected to multiple episodes of land use impacts over the last millennia, while others are just being impacted for the first time. In principle it should be possible to use records from the long-impacted catchments to anticipate the future trajectories of the still pristine catchments.

With this background in mind a workshop was convened in November 2012, hosted by the National University of Singapore (NUS). Twenty-five participants, including experts from Germany, Singapore, Japan, Malaysia, Indonesia, Australia and Thailand represented the disciplines of archeology, environmental history, geomorphology, hydrology, remote sensing, engineering, soil science, and biogeochemistry. The goal of this meeting was to set up a regional working group on soils and sediments (WGSS) for Asia and to coordinate its activities.

After two days of discussion, the participants reached the following resolutions:

- The Asian-WGSS will be convened and led by Dan Penny (University of Sydney, Australia) and Lu XiXi (NUS).

- Initial efforts will build on existing work in a few case studies: (A) Angkor and the Tonle Sap Lake in Cambodia; (B) the Huang He in China; (C) the Palembang River catchment in Indonesia; (D) the Saru River catchment in Japan and; (E) the Ping River catchment in Thailand.
- A panel discussion on the Asian perspectives on soils and sediments was held at the Asia Oceania Geosciences Society conference in Brisbane in June 2013.

- Further meetings of the Asian WGSS will be held to coordinate activities.

In addition, there was considerable discussion regarding a common strategy for an Asia-wide analysis of human-environmental interaction with a focus on soils, sediments and river systems. Before the recent rise in greenhouse gases, the most profound cause of global human impact during the Holocene was the onset of settled agriculture several thousand years ago, and there is now a call for the beginning of the Anthropocene to be defined by this major change (Balter 2013). The period of settled agriculture would also clearly be a meaningful time scale for Asian WGSS research; however, unlike the boundaries between geological epochs, the onset of settled agriculture is diachronous - which is a problem for stratigraphers, but provides an interesting research question for the WGSS.

Settled agriculture was established in NE China by 8000 BP and in NW South Asia by 7500 BP. It subsequently spread across China and South Asia, arriving in Taiwan about $400 \mathrm{BP}$, and then extending across the mountains of mainland Southeast Asia, joining with a second wave of agricultural development coming up from South Asia, what is now Myanmar and Thailand, within the last 500 years (Elvin 2004; Elvin and Liu 1998; Wyatt 1984; Stark 2006; Boyle et al. 2011; Kaplan et al. 2011). While there are ancient origins for agriculture in insular SE Asia, the conversion of large areas from native vegetation only occurred within the last few centuries. These usage patterns are wonderfully captured in animated form for the period 8000 BP to 100 BP at http://grkapweb1.epfl. ch/pub/KK12_totallanduse.mov (Kaplan et al. 2011). Figure 1 also shows the amount of land employed for both extensive and intensive uses as at AD 1, when agriculture extended over most of China, South Asia and much of peninsula SE Asia, and then again in AD 1850, when there were few places left not affected by agriculture. 

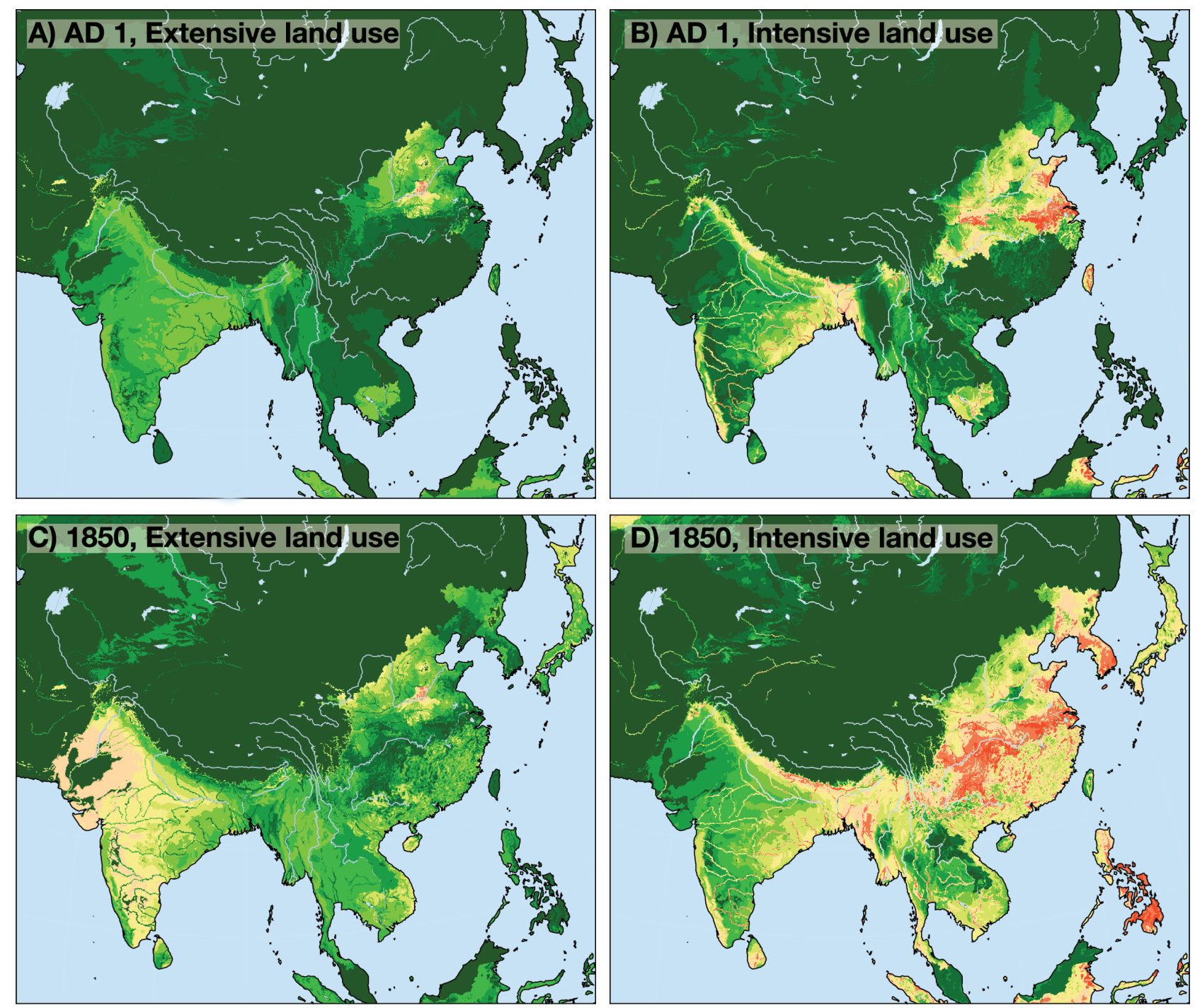

0.1

0.3

0.5

0.7

0.9

Fraction of gridcell under land use

Figure 1: Amount of land employed for both extensive (A and $\mathbf{C}$ ) and intensive (B and $\mathbf{D})$ uses as at AD 1 (A and $\mathbf{B}$ ), and then again in $A D 1850$ ( $\mathbf{C}$ and $\mathbf{D})$. The land use patterns were extracted from the animation shown at http://grkapweb1.epfl.ch/pub/KK12_totallanduse.mov (Kaplan et al. 2011).

This large-scale conversion into agricultural land continues nowadays in Malaysia and Indonesia with the replacement of lowland rainforest by rubber and oil palm plantations and large-scale deforestation, which began after the Second World War (e.g. De Koninck et al. 2011). Recent research by the NUS has shown that in Johor, southern peninsula Malaysia, conversion of lowland rainforest to rubber and then oil palm plantations in the last ca. 60 years has produced sedimentologic evidence in valley floors, similar to those seen in catchments in Australia and the USA when impacted by the European settlers.

The wave-like development of settled agriculture in much of Asia provides an opportunity for the PAGES Focus 4 Theme on soils and sediments to develop chronologies of disturbance in fluvial networks that have been subject to diachronous agricultural development. These fluvial networks may also have been affected differently by climate variability during the Holocene. For example, the Huang He in northern China was most affected by agriculture and Holocene climate changes, while the rivers of
Johor are likely to have been affected mainly by very recent land cover conversion. Similarly, much of the large-scale land-cover change in the montane mainland of SE Asia occurred within the last century.

By studying catchments of similar size and topography, as well as the onset times of settled agriculture in the last 2000 years, it should be possible to determine the impact of agriculture, as climate variability was relatively small during this period. However, for catchments where settled agriculture began in the early Holocene, a climate change signal is to be expected given the mid Holocene experienced the largest shift in climate since the deglaciation. Applying this framework to the Asian working group on soils and sediment will inventory current knowledge of both climate change and agricultural beginnings. The empirical results from such research could be used to test soil erosion and sediment flux models being developed by the "geomorphic prediction" working group (http://geomorphicprediction.geo.arizona.edu). Ultimately, we hope to facilitate a better understanding of fluvial response to land use and climate change in the most populous, biodiverse and dynamic region on Earth.

\section{AFFILIATIONS}

'Department of Geography, University of Bonn, Germany ${ }^{2}$ Asia Research Institute, National University of Singapore, Singapore

${ }^{3}$ Geography Department, National University of Singapore, Singapore

\section{CONTACT}

Thomas Hoffmann: thomas.hoffmann@uni-bonn.de SELECTED REFERENCES

Full reference list under:

http://www.pages-igbp.org/products/newsletters/ ref2014_1.pdf

Balter M (2013) Science 340: 261-262

Hoffmann T et al. (2010) Global Planet Change 72: 87-98 Stark M (2006) Annu Rev Anthrop 35: 407-432

Syvitski JPM (2005) Science 308: 376-380

Wasson RJ (1996) PAGES Workshop Report, Series 96-2: $51 \mathrm{pp}$ 